\title{
Battery Energy Storage System Integration in a Combined Cycle Power Plant for the Purpose of the Angular and Voltage Stability
}

\author{
François Kremer ${ }^{1,2(\bowtie)}$, Dominique Remy ${ }^{1}$, Wangue Merville ${ }^{1}$, \\ Stéphane Rael ${ }^{2}$, and Matthieu Urbain ${ }^{2}$ \\ ${ }^{1}$ General Electric, Rue de la découverte, 90000 Belfort, France \\ francois.kremer@ge.com \\ ${ }^{2}$ GREEN, Université de Lorraine, 54500 Vandoeuvre lès Nancy, France
}

\begin{abstract}
The introduction of the renewable energy sources in the electrical network is something necessary in the ecological transition context. This integration forces the grid operators to change the way to generate electrical power by favoring sustainable sources against traditional techniques. That means, adapt the grid code to provide the same energy quality for the end-customer despite the growing grid instability. Fast acting systems become more and more necessary to stabilize the grid by limiting the frequency, power and voltage swings. The integration of an electrochemical storage system at different connection points of the network is a solution technically studied over the last decade. In this article, the BESS will be connected inside a powerplant with a focus on the hybridization of the sources. Services as the angular stability and the plant voltage regulation are described however services concerning frequency regulation or plant design improvement are not approached. The hybridization concerns the synchronous machine, the associated excitation, the storage and the control system. The expected benefits for the grid operators are the enhancement of the flexibility, the robustness and the electrical quality towards a more and more constraining grid instability.

Different services will be presented describing the integration concept, the potential connections, the sizing or some operating profiles. These services will concern the small-signal stability, the transient angular stability, the voltage regulation and the voltage disturbances (flicker, harmonics...). A simulation has been done with Matlab/Simulink ${ }^{\mathrm{TM}}$ to show the benefits of the solution under the technical requirement specification $n^{\circ} 6$ of the French grid operator.
\end{abstract}

Keywords: BESS $\cdot$ Thermal power plant $\cdot$ Angular stability $\cdot$ Voltage stability

\section{Introduction}

The market of electricity is today undergoing change due to the introduction of renewable power sources. These integrations and environmental challenges result in strong destabilization of the electricity grid. It can be noticed a loss of traditional generation groups leading to an increasing active and reactive power variability. A way 
to fight against theses disturbances is to improve the flexibility of the network. This is defined by Belgian TSO as "the capacity of the system to react towards un-predictable and predictable grid changes while ensuring the security, the reliability and the efficiency of it" [1]. A mix of flexible sources, as generation units (Combined Cycle Gas Turbine, biomass, hydraulic, nuclear ...), energy storage systems and a predictive management of the demand at the Point of Connection (PoC) are necessary to ensure the stability of the electricity network [2].

Many articles explain the benefits of BESS connected at different points of the grid and whose profitability is demonstrated thanks to grid ancillary services [3-6]. Ancillary services being the technical capacity of the system to meet the optional or mandatory requirements imposed by the TSO to flexibility sources in the grid code. These requirements are related to the frequency, the voltage and the angular stability or the grid restauration in case of failure (black start). The ancillary services provided by the BESS have the disadvantage to have a limited time duration due to the limited energy reservoir. Therefore, the historical way of generation like CCGT (Combined Cycle Gas Turbine) or hydropower stations are mainly used to perform theses grid services. These sources offer a continuous grid support despite their low reactivity due to mechanical time constants.

A stable quality of service should be maintained, defined as the capacity to stay and return at a stable operating point, with the ancillary services, which are retributed and structured in 3 categories:

The angular stability: The synchronous generator is connected to the grid and rotate at the synchronous speed due to an elastic torque created by the electrical values [2]. Some events could disturb this synchronization leading to a trip of the production units. The angular stability is the capacity to be and stay connected to the grid. In other words, to maintain the internal load angle of the machine within certain limits depending on the active and reactive power. The de-synchronization, which is nothing more than a loss of control of the internal angle, can be caused by severe load variations called transient stability or small disturbances, called small-signal stability [7].

The voltage stability: The grid equipment is defined for one single voltage value, and the variation outside the nominal operating range involves material destruction, early ageing, additional losses, ... This variation can be induced by the imbalance between the power consumption and the power generation (like the frequency regulation) or some changes of the network topology. To reduce the imbalance, a primary, secondary and tertiary reserves are used [3].

The frequency stability: The frequency stability aim is to maintain the balance between the power generation and the power demand, different control loops have been implemented for this purpose. These regulators avoid, first, the frequency collapse (frequency containment) then re-establish the frequency to its initial value (frequency restoration), and finally restore manually the reserve (replacement reserve).

This document proposes an improvement of the grid flexibility by combining two complementary sources of flexibility which are a thermal power plant (CCGT) and the battery energy storage system. The powerplant reference chosen in the article does not impact the way to use the BESS as long as the services focus on the angular and voltage stability. Indeed, the equipment concerned by these functions are the 
synchronous machine and its excitation system, the storage system and the control which are comparable for different powerplants. Only the single line diagram or the PoC might be modified.

The hybridization of a BESS and a combined cycle power plant is not achieved yet. Indeed, the West Burton power plant integrates a Li-ion storage system to provide EFR. However, no software integration has been performed to hybridize the gas turbine and the BESS. Another example can be the hybridization of an aero-derivative gas turbine in Norwalk, California with a BESS by General Electric. The system can provide frequency response, voltage support, spinning reserve and blackstart. In this example, the power ratio between the BESS and the gas turbine is important $(20 \%)$ compared to our application in which the ratio will be less than 5\%. The hybrid solution presented in this paper proposes a complete control integration, a battery optimization size and known services, but provided by both systems.

After a brief description of each system, services achievable by the hybridization are explained in detailed with different topologies and control philosophies. Finally, a hybrid service is simulated under the French grid codes rules.

\section{Hybrid System}

\subsection{Combined Cycles Gas Turbine}

The CCGTs are composed by a Gas Turbine (GT) associated with a Steam Turbine (ST). The concept of this plant is to improve the overall Power Plant efficiency by using the hot exhaust gas to boil water in a Heat Recovery Steam Generator producing steam

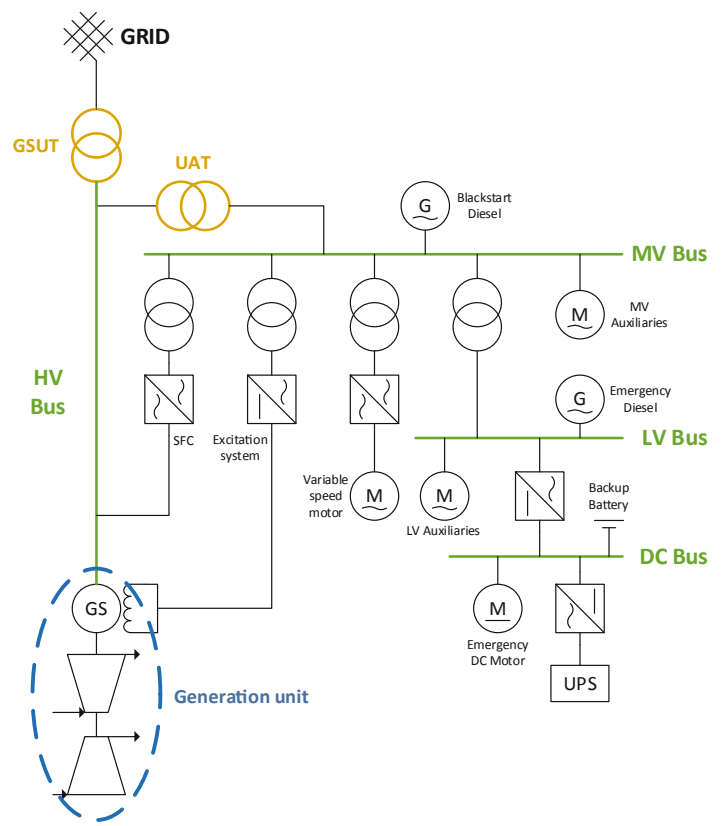

Fig. 1. Basic Single Line Diagram of CCGT with gas turbine auxiliaries 
to feed the ST. The electricity is produced with synchronous generators driven by the turbine(s) shaft(s). One can approximate that, the power delivered by the ST is roughly the half of whole GT (Fig. 1).

On the electrical side, the generator is directly connected to the grid by means of a HV bus called the Insulated Phase Bus and the Generator Step-Up Transformer (GSUT). All auxiliaries as pumps, motors, water tanks or inverters are fed via the Unit Auxiliary Transformer (UAT) and the auxiliary buses (MV, LV or DC Bus) connected to the HV.

\subsection{Battery Energy Storage System}

Concerning the electrochemical storage, the lithium technology is chosen for its high cycling capacity and for its fast charge and discharge possibilities. To manage this electrical flux, the BESS needs power electronics to drive, to convert and to regulate the transferred energy. The other main elements of the storage device are the BMS (Battery Management System), the MV/LV or HV/LV transformer depending of the point of connection and the controllers which shall manage set-point signal, communication and dispatch instruction interfaces for battery, converter and grid system.

The integration of a BESS into the CCGT in term of layout, connection and control shall be designed carefully as it has an influence on plant equipment. Difficulties is even worse when the BESS is added to an existing plant.

\section{Angular and Voltage Stability Services}

Depending on the point of connection of the BESS, the provided services are different. A stand-alone BESS due to its location will improve either the distribution or transmission grid whereas the PI-BESS will improve the distribution services and the plant operability.

A non-exhaustive list of services is presented in a paper under acceptance, the services discussed here focus only on the angular and voltage stability as shown in the next table. Their aims are to enhance the operability of the generator by avoiding the disconnection or by supporting the auxiliary bus (Table 1).

Table 1. Services concerning angular or voltage stability

\begin{tabular}{l|l}
\hline \multicolumn{2}{l}{ Services names } \\
\hline QE1 & Transient angular stability \\
\hline QE2 & Small-signal stability \\
\hline QE3 & Voltage regulation \\
\hline QE4 & Disturbances reduction \\
\hline
\end{tabular}




\subsection{QE1: Transient Angular Stability}

The transient angular stability is a deviation of the internal load angle of the machine due to a severe and temporary disturbance. Criteria considered is a voltage dip or a sudden fall of the voltage greater than $10 \%$. The consequence of the voltage dip is the reduction of the resistant electrical torque. Without brake, the generator will accelerate up to the default suppression threshold and then suddenly decelerate trying to stabilize the rotational speed. Sudden accelerations of the generator shaft will increase the internal load angle with the risk to desynchronize the synchronous machine from the grid and force the generator to disconnect. In that case the synchronous torque between the grid and the generator must be maintained by the excitation system by boosting or damping the flux in the generator air-gap.

In case of a stator voltage dip, the PI-BESS can improve the angular stability by providing or by absorbing an instantaneous additional reactive or active power. The principle is the equal area criterion which aim is to have a "net-zero" energy balance [7].

The integration of such a control needs to operate in combination with the excitation, without bringing power oscillation between the two different regulators. In the case of new units, a centralized and common controller should be implemented to manage both systems at the same time to propose better robustness of the whole system. In the case of powerplant retrofits, the communication cannot be easily implemented. The decentralized control, which aim is to maintain the global stabilization by locally support the grid, will be the adequate solution to use. For instance, General Electric has implemented decentralized control with an aeroderivative turbine and a BESS in California.

In any case, the PI-BESS power supply will be limited by the converter size and a voltage regulation loop must be implemented to support locally the generator and increase the LVRT (Low Voltage Ride Through) compliance. The point of connection will be either on the MV bus close to the UAT with limited power or on the HV bus to obtain a better impact on the transient angular stability (Fig. 2).

Another way to integrate the PI-BESS, is to replace the excitation system by the BESS, with DC/DC converter between the exciter and the battery. In that case, the conventional excitation bridge (one way) is substituted by a bidirectional AC/DC converter to charge and discharge the battery and an additional DC/DC converter to provide the DC field current to the generator. This configuration could allow the stabilization by providing at the same time, an over boost of the excitation and a damping power with the inverter. This deep integration will contribute to have a better response of the entire system but will force to change a lot of equipment and usage, which cannot be easily provided on plant retrofit (Fig. 3).

[3] estimates a high-power BESS, around $10 \%$ of the generator nominal power to get a significant impact on the distribution lines. However, a hybrid solution with a capacity of $2 \%$ of the generator nominal power, for the $1^{\text {st }}$ integration case (retrofit) is impacting as shown in the last section. No study has been achieved for the second case. The mechanism of valorization does not exist yet and the economic profitability for the angular stability cannot be considered. It is the primary difficulty during a commercial bid, to translate this technical benefit in economic value. 


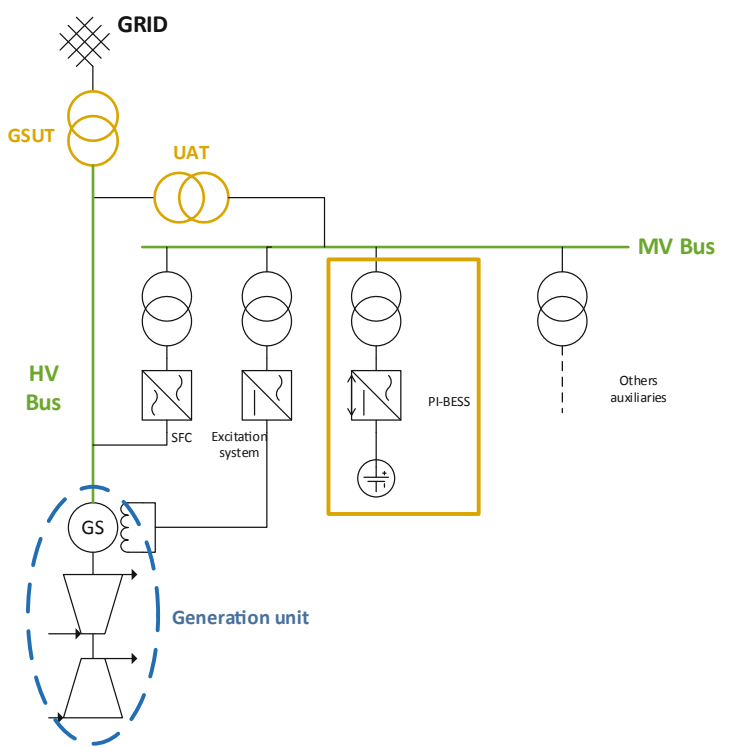

Fig. 2. Integration of the BESS in parallel to the excitation system.

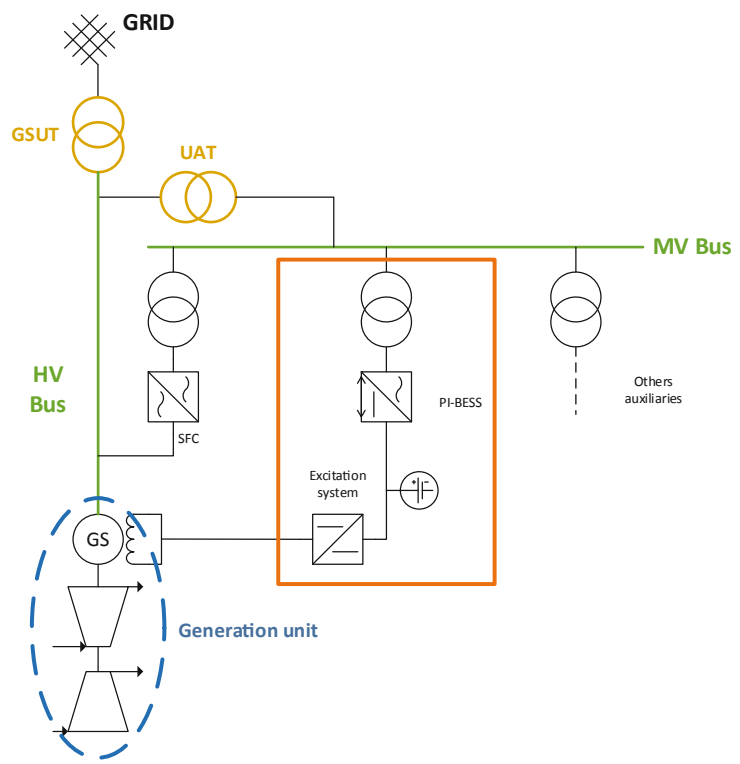

Fig. 3. Integration of the BESS in series with excitation system. 


\subsection{QE2: Small-Signal Stability}

Unlike the transient angular regulation, the small-signal stability must be insured continuously and is induced by small oscillating instabilities $(0.2$ to $2 \mathrm{~Hz})$ around the operating point. These oscillations, apparent on the voltage, are normally smoothed by the damping torque of the synchronous machine. [8] explains that the modern excitation systems usually increase the synchronism torque (smoothing the severe disturbances) however it reduces the damping torque. In doing so, the machine is more sensitive to small-signal disturbances. A supplementary control layer, called Power System Stabilizer (PSS), is generally added to the Automatic Voltage Regulator (AVR) to deal with the inter-area oscillations using a damping torque.

The damping torque can be produced, as explained in the previous section, with a control loop of the excitation system (PSS) or with FACTS. The FACTS systems (Flexible AC Transmission System) are used to improve the voltage quality on transmission lines by providing only reactive power with power electronics devices. Similarly, to the FACTS, the PSS loop could be implemented in the PI-BESS to generate the appropriate power to smooth the rotor load angle oscillations.

The use of this service must be carefully adapted to the location. Indeed, a wrong location can amplify the small signal disturbances. To avoid this, fast communications between the excitation system and the storage system are justified. The power needed for small signal disturbances is unknown. Especially if the PSS control loop is dispatched both in the excitation system and the BESS, which will highly complexify the stability study.

As the service QE1, the storage system can be integrated either on the HV bus or the MV bus depending the amount of the power transfer needed. Further study will be driven to size the storage system and study the control stability. The benefit of the solution cannot be remunerated but proposed for a better energy quality.

\subsection{QE3: Voltage Regulation}

As is it usually the case in the transmission grid, the voltage regulation is based only on reactive power control for inductive load. The regulator will control the amount of reactive power and the response time. In the case of PI-BESS, the reactive power is essentially provided by the generator due to the power limitation of the converter characteristics. The reactive power is produced with phase shift between the current and the voltage on AC side. The battery energy used will only compensate the loss in the converter and globally stay at the same state of charge (SoC). It is the reason why the limiting factor for this service is the maximum converter power and not the stored energy.

The battery will support the local MV area (i.e.: voltage dip caused by pump start) or help the transient response of the synchronous machine by providing faster reactive power $(<100 \mathrm{~ms})$. Indeed, the small power of the BESS compared to the synchronous generator MVArs limits its effect on the generator stability. The PI-BESS can be used as a boost to complement the excitation system, as shown Fig. 3. This topology will bring better and faster control than the actual technology without problem of voltage drop. The replacement of the actual robust and controlled excitation system by a new system with battery is useless without merging battery services. 
[3] proposes a sizing method for the converter around few MVARs but it has to be considered that the cost of the solution is not competitive compared to the passive solutions (capacitors banks, tap changer, AVR in the synchronous machine) for distribution lines. In our case, the passive solutions are not relevant since the excitation system itself is enough to solve this issue. The integrated asset will focus on all aspects of the quality of energy by doing multiple services and not only QE3.

The used of the storage system and the way to connect and control it is like QE1QE2 services. In that case, the magnitude can be different depending on the wished effect on the plant. Indeed, $20 \%$ of rated generator power is needed to impact the overall plant but $2 \%$ is enough to support pump start on the MV bus.

The added value of this service is limited since the synchronous generator is designed to provide or absorb an important volume of MVARs. However, the additional MVARs can be an extra-service without costing more during the sizing.

\subsection{QE4: Disturbances Reduction}

The stability of the electrical grid depends on the generation units, the transmission and distribution operators and the consumers. Indeed, disturbances can be created at each level of the grid. This energy quality is assessed with electrical factor such as the voltage continuity (long or short power interruptions) and the quality of the voltage (amplitude or frequency variation, distortions or unbalances). At local level, the generation assets help for the voltage continuity, but their main usage is to maintain the quality of the grid according to the applicable grid code. In France, EN50160 and IEC61000 are the standards which define criteria for normal operation conditions for the voltage quality.

The disturbances which deteriorate the voltage quality are the flicker, the voltage drops, the harmonics, the overvoltage and the voltage phases unbalances. The usual methods (passive filters, AVR and PSS, capacitor banks, ...) to compensate the disturbances can be replaced by power electronics or in that case a BESS. For instance, in the case of harmonic distortions the converter will be used as an active shunt compensator injecting the adequate harmonic current. As every consumer on the grid, the auxiliary bus has the duty to manage the quality of the voltage. With the connection on the transport grid, the short circuit power is large enough to insure a good voltage quality. However, on islanding mode (weak grid), the local installation needs to have harmonic filters to provide the correct operation due to a small short circuit power. The PI-BESS is a solution to regulate the power quality.

The benefit of this service cannot be directly financially estimated but needs to be translated in an improvement of the grid operation (losses reduction) or a decrease in grid quality financial penalties. An investment shift can be another benefit, using the asset instead of installing passive solutions.

The BESS sizing depends on the point of connection and the level of disturbances to damp, it will be in the order of few MVA for few minutes of use. This hybrid solution can be used for blackstart service which is usually ensure with diesel generator and harmonics filter. The challenge will be to size and control correctly the storage system. 


\section{Sizing and Benefit of the Solution}

The benefit of such a system is difficult to understand and to evaluate without a retribution from the TSO. The interest of the BESS support can come to the spotlight with the increasing penetration of renewable energy, asking for more stringent Grid Code requirement. To demonstrate the interest to implement this solution, a simulation on the transient angular stability has been achieved demonstrating the technical benefit of such a solution.

The French grid operator RTE imposes different technical requirement specification which need to be respected by the installation connected on the transport grid $(>50 \mathrm{kV})$ [9]. The sixth specification concerns the dynamic voltage regulation and the transient angular stability. After a robustness evaluation with margin calculation on different operating points, a SMIB (Single Machine - Infinite Bus) model is tested for a variation of $2 \%$ on the voltage set-point injected in the excitation system. This model needs to be tested with two different values of the grid impedance and pass the compliance criteria (response time, overshoot, ...). The assessment of the excitation system had been achieved under these conditions.

The model is built with the Simscape library on MATLAB-SIMULINK. The synchronous machine, the three-Phase Transformer (Two Windings) and the ThreePhase Series RLC Branch models are the Simscape models. A small-signal lowfrequency linear circuit model is implemented for the inverter. It models the average behavior of the inverter and the control loops (Power, Current and DC Voltage) using Concordia and Park transformation as explained in [3] (Fig. 54). The battery is supposed as a constant voltage source due to the small simulation time (few seconds). Finally, the excitation system is model by a ST4B presented in the IEEE 421.5. The simulation is validated with the $6^{\text {th }}$ specification of the French grid code.

Considering the overall controller philosophy, no control loop of it has been considered in this paper. The reference of the storage system controller is immediately the power variation measured on the generator shaft. The detailed design of the control loop will follow in a further article.

The parameter use for the simulation are taken from a $2 \times 1$ 7HA.02 powerplant of General Electric loaded at $65 \%$. The short circuit power is around 10000 MVA with a lagging power factor at $0.9 \mathrm{pu}$, a grid voltage at $95 \%$ and a generator voltage around $103 \%$ of the nominal value.

To prove the benefit of the PI-BESS, the behavior is checked without the storage system, with active power control and with active and reactive power control. The test consists of adding immediately $20 \mathrm{MVAr}$ on the grid side. Without hybridization, the generator voltage reaches $105 \%$ and the angle have 2 degrees of deviation. The power control of the battery allows to smooth the transient variation of the angle. However, the $6 \mathrm{MW}$ deliver cannot change the voltage deviation. Using the battery with active and reactive control, the variability of the electrical variables is damped. Indeed, the angle deviation is only 1 degree and the generator voltage reaches $104 \%$. The reactive power profile is a step of $8 \mathrm{MVAr}$ absorb by the BESS.

These logical results prove an effect of the battery for the grid stabilization and allow to estimate the active and reactive power involved. With an adequate control, this 
benefit can improve the size of the battery and help the plant operator to meet stringent grid requirements (Fig. 4).
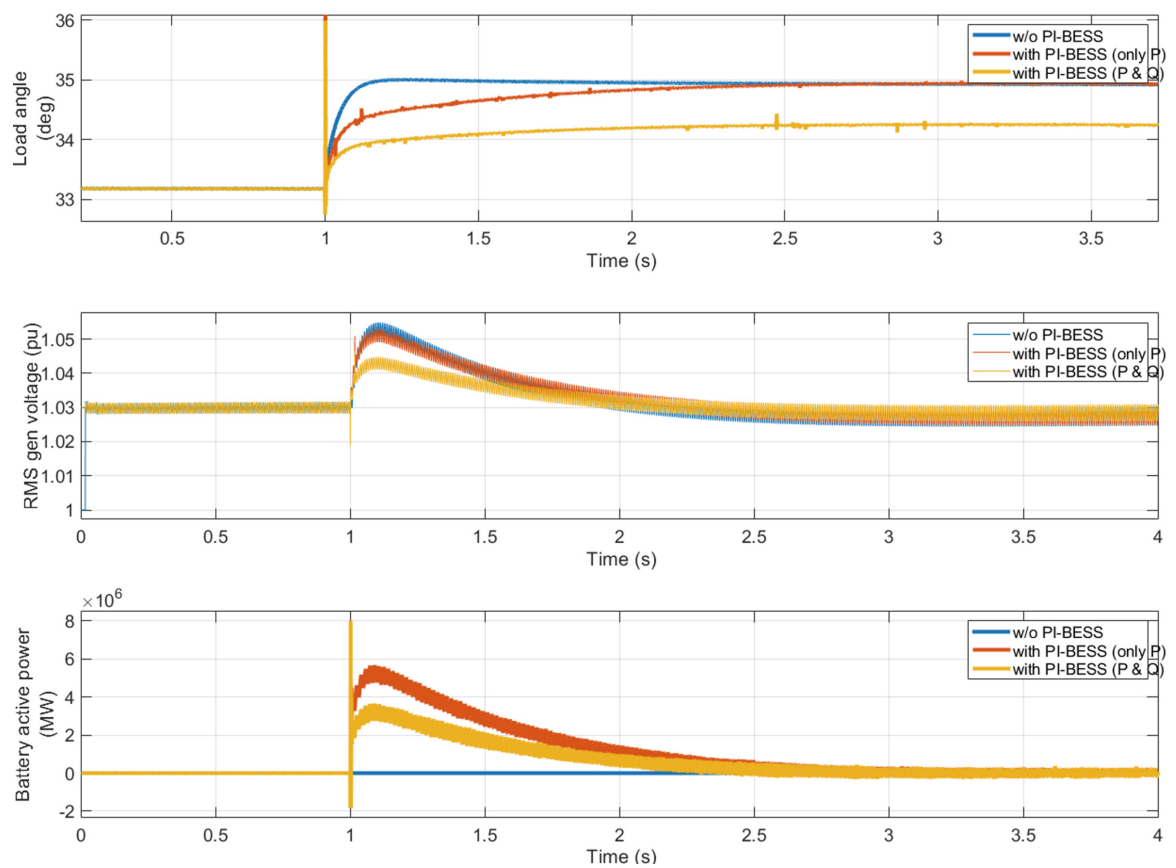

Fig. 4. Synchronous generator load angle, HV bus voltage and battery power variation under a 20 MVAr load shedding

\section{Conclusions}

Enhancements of the grid voltage quality and angular stability with an integration of BESS in a combined cycle are proposed in this article. These improvements concern the transient angular stability, the small-signal stability, the local voltage regulation and disturbances attenuation. The PI-BESS integration inside a power plant induce hardware and software development which will be plant specific and will be fine-tuned to avoid instability in case of large grid disturbances. As currently, there is no remuneration associated to the functionalities proposed by the article, we have decided to perform the first set of study via computer modelling only considering the French grid code specifications. Operation with and without PI-BESS has been shown. The first simulation results allow to validate these concepts and to estimate the appropriate capacity of the battery that would be needed to reach a significant impact on the generator dynamic services.

Acknowledgment. This paper is part of the FLEXITRANSTORE project. This project has received funding from the European Union's Horizon 2020 research and innovation program under grant agreement No. 77440 . 


\section{References}

1. Electricity scenarios for Belgium towards 2050, ELIA, November 2017. http://www.elia.be/ / media/files/Elia/About-Elia/Studies/20171114_ELIA_4584_AdequacyScenario.pdf. Accessed 27 May 2019

2. Mémento de la sûreté du système électrique, RTE, Technical report, ISBN - n 2-912440-13-0 (2004). www.rte-france.com. Accessed 27 May 2019

3. Delille, G.M.A.: Contribution du Stockage à la Gestion Avancée des Systèmes Electriques: approches Organisationnelles et Technico-économiques dans les Réseaux de Distribution. Sciences de l'ingénieur [physics], Ecole Centrale de Lille, Français, <NNT: 2010ECLI0016> (2010)

4. Fitzgerald, G., Mandel, J., Morris, J., Touati, H.: The Economics of Battery Energy Storage: How Multi-use, Customer-Sited Batteries Deliver the Most Services and Value to Customers and the Grid. Rocky Mountain Institute, September 2015. http://www.rmi.org/electricity_ battery_value. Accessed 27 May 2019

5. Christiansen, C., Murray, B., Conway, G.: Energy storage study: a storage market review and recommendations for funding and knowledge sharing priorities. AECOM, July 2015. https:// arena.gov.au/assets/2015/07/AECOM-Energy-Storage-Study.pdf. Accessed 27 May 2019

6. Sidhu, A.S., Pollitt, M.G., Anaya, K.L.: A social cost benefit analysis of grid-scale electrical energy storage projects: evaluating the smarter network storage project. University of Cambridge, EPRG Paper, May 2017. https://www.eprg.group.cam.ac.uk/wp-content/uploads/ 2017/06/1710-Text.pdf. Accessed 27 May 2019

7. Kundur, P.: Power System Stability and Control. Electric Power Research Institute, Power System Engineering Series. McGraw-Hill (1994). ISBN 0-07-035958-X

8. Alkhatib, H.: Etude de la stabilité aux petites perturbations dans les grands réseaux électriques: optimisation de la régulation par une méthode métaheuristique, Automatique/ Robotique, Université Paul Cézanne - Aix-Marseille III, Français (2008)

9. Documentation technique de référence, RTE, p. 699 (2009). http://clients.rte-france.com/htm/ fr/mediatheque/telecharge/reftech/16-10-2017_complet.pdf. Accessed 27 May 2019

Open Access This chapter is licensed under the terms of the Creative Commons Attribution 4.0 International License (http://creativecommons.org/licenses/by/4.0/), which permits use, sharing, adaptation, distribution and reproduction in any medium or format, as long as you give appropriate credit to the original author(s) and the source, provide a link to the Creative Commons license and indicate if changes were made.

The images or other third party material in this chapter are included in the chapter's Creative Commons license, unless indicated otherwise in a credit line to the material. If material is not included in the chapter's Creative Commons license and your intended use is not permitted by statutory regulation or exceeds the permitted use, you will need to obtain permission directly from the copyright holder.

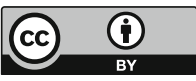

